micropolitics of defining terms of reference for prizes are constantly in play - who writes the review of potential candidates, and the jockeying in the committees and in the academy's plenary meeting that influences the outcome of the process. The academy has been known to override committee recommendations, and infighting, ignorance and fixation on pet ideas were perhaps more prevalent in the early days, when review procedures were less systematic and a few dominant personalities held sway. But Friedman shows how, even today, when one looks behind the scenes the Nobel prize belies the popular myth of being a dispassionate, neutral, disinterested process.

Friedman's tale is never dull. Although not intended as a scholarly work, the book is not mere gossip. Aimed mainly at a broad audience, it nevertheless has a separate section of elaborate notes for historians and students of the politics of science wishing to delve deeper. What irritates is the cuteness of some subheadings put in to engage the popular reader. Also, with all the focus on conflicts and controversial events, one wonders what happens in the cases of more peaceful convergence around prizewinning candidates, or whether, in such an extraordinary setting, those don't exist.

Aant Elzinga is in the Department of the History of Ideas and Theory of Science, University of

Göteborg, SE 40530 Göteborg, Sweden.

\section{Sex appeal of a musical insect}

\section{Katydids and Bush-Crickets: \\ Reproductive Behavior and Evolution of the Tettigoniidae \\ by Darryl T. Gwynne \\ Cornell University Press: 2001. 344 pp. $\$ 42.50$}

\section{Marlene Zuk}

With great reluctance, I have decided against my initial impulse to give this book to everyone I know for Christmas. Some friends might appreciate it, but I can't quite see my Texas in-laws expressing much enthusiasm. This caveat notwithstanding, Katydids and Bush-Crickets is a fascinating and enjoyable read, full of both charming trivia and scholarly insight. The book is brimming with 'did-you-knows?': for example, the term diapause (the temporary cessation of development in insects) was coined by the renowned Harvard expert on ants, William Morton Wheeler, in his 1893 thesis on katydids. The book is also beautifully illustrated, with many line drawings, breathtaking colour plates, and figures that are all redrawn from their original source - a welcome touch of clarity and uniformity that is absent

\section{A turn-up for worms}

Here are two examples of the "multiple variations on a theme" that comprise the diverse species of marine worms, or polychaetes - Eupolymnia (right) and Hediste diversicolor. Polychaetes by Greg W. Rouse and Fredrik Pleijel (Oxford University Press, $\{99.50, \$ 175)$ examines these animals, which are found in nearly every marine habitat.
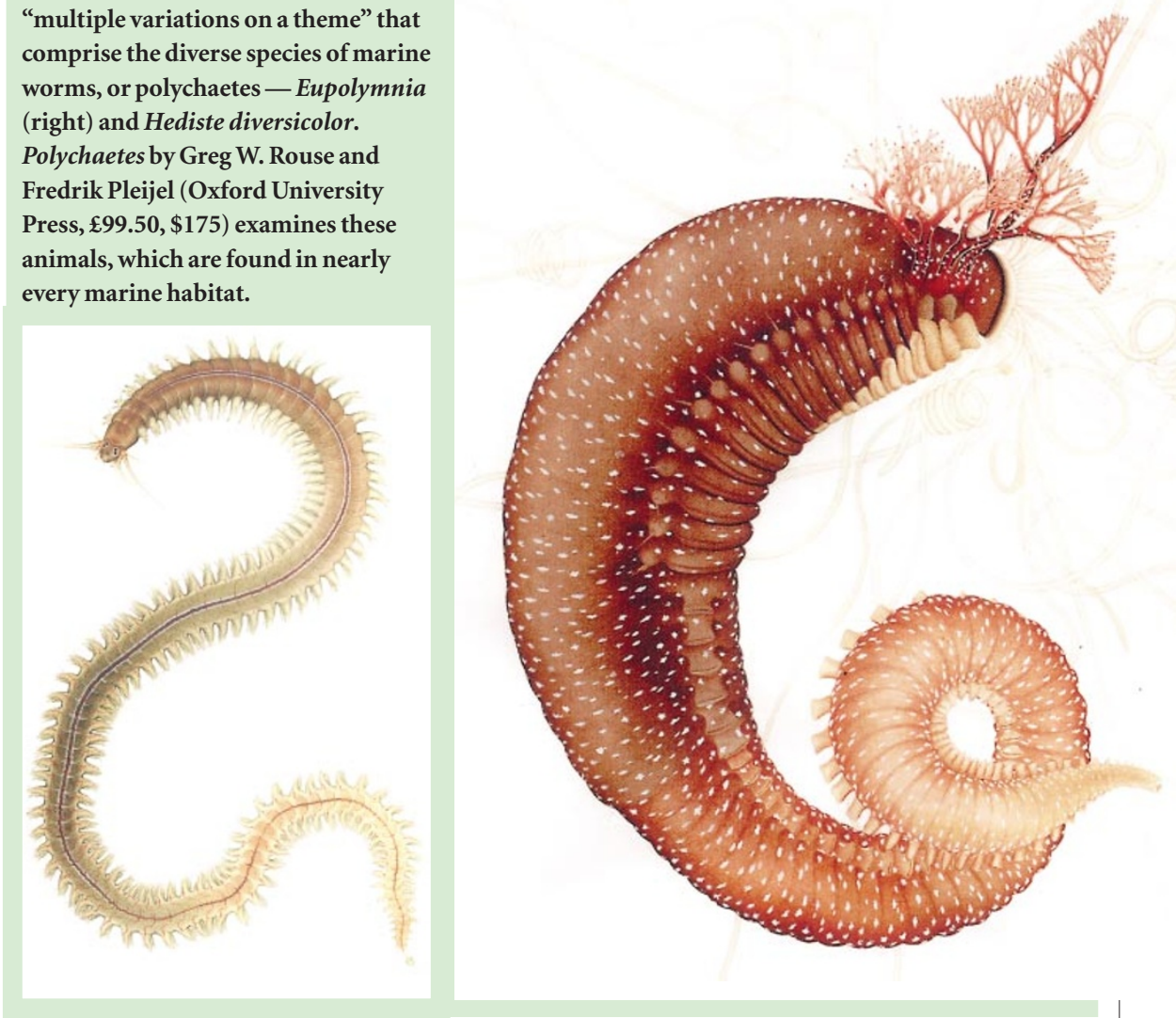

in many such books. Virtually all of the chapters begin with pertinent and amusing quotations from sources ranging from Oliver Wendell Holmes to Dean Martin.

Why is this group of insects - called katydids in North America and bush-crickets in Europe - so interesting? Although Darryl Gwynne provides information on diversity, evolution and the economic importance of the family, the focus of the book, and the answer to the question, is the katydid sex life. Unlike most insects, and indeed most animals, katydid males contribute more than just sperm when mating. They generally provide females with a nutritious parcel, the spermatophylax, which is attached to the sperm-containing ampulla. The female consumes the spermatophylax after mating, while the sperm move into her reproductive tract.

This nuptial gift can represent up to $40 \%$ of the male's body mass, and hence is not easy to produce. Males may mate only once every few days, garnering the resources to manufacture one of these massive meals between mating. The hefty donation has important implications for sexual selection, because the general rule is that the reproductive success of males is limited only by the number of females they can inseminate, rather than by the investment they make in producing offspring. This is likely to be far more variable than the factor that generally limits female reproductive success - the number of offspring they can produce and (where appropriate) rear. Because females in a species usually make the greater investment, sexual-selection theory predicts that females will benefit by maximizing the quality of their offspring, but males will benefit more from maximizing the quantity.

All that is reversed in katydids and in several other organisms, including seahorses and their relatives the pipe-fish, as well as a handful of birds and insects. If males do not merely produce a dab of semen, but must proffer a costly gift to females before mating, they would be expected not only to be choosy about their mate, but also to be environment in a way that males in other species are not. Such a reversal of sex roles provides a crucial test of current theory on how the sexes are expected to differ.

How did the spermatophylax evolve? Gwynne evaluates two hypotheses. The that males provide females with a meal because it increases the fecundity of the female or the quality of the offspring she produces, and hence increases the male's fitness along with that of the female. According to the ejaculate-protection hypothesis, in contrast, the spermatophylax serves to keep sensitive to the availability of resources in the paternal-investment hypothesis suggests 
females busy eating it while sperm are transferred. Males providing larger gifts therefore gain a larger proportion of fertilizations.

In a careful dissection of experiments on a variety of species, Gwynne concludes that the paternal-investment hypothesis has received the more support; in many katydids, the ampulla is completely empty long before a female has finished her gelatinous meal.

Nevertheless, much remains to be discovered about katydids. Indeed, one of the book's strengths is the prevalence of ideas for further research - there's a possible dissertation project on virtually every page. Why, for example, have so few katydid species lost acoustical function, compared with their equally musical relatives the crickets? What favoured the occasional evolution of parthenogenesis in this unlikely-seeming group? Why do some katydids mate only once? The section on risks and survivorship is particularly dramatic: "in nature, death usually comes from a plethora of hostile forces", including parasitoid flies that home in on the male's calling song, horsehair worms that burst from the body cavity like lethal spaghetti, as well as bats, frogs, birds and fungi.

One can quibble with any work of this magnitude, and I did my share. The references on a few topics, such as the role of sexual selection in speciation, were curiously outdated. Sexual-conflict theory - the conflict between males and females over mating - is a relatively new, hot topic in sexual selection, but is mentioned rather briefly; its explicit incorporation into ideas about spermatophylax evolution might have been fruitful. Gwynne draws a distinction between so-called passive and active female choice, a dichotomy I have always disliked. These bits of carping aside, Katydids and Bush-Crickets is a book to share with all students and professionals in ecology and evolutionary biology — and, who knows, maybe also with a few relatives at Christmas. Marlene Zuk is in the Department of Biology, University of California, Riverside, California 92521, USA.

\section{More biology}

\section{Carnivore Conservation}

edited by John L. Gittleman, Stephan M. Funk,

David Macdonald \& Robert K. Wayne

Cambridge University Press, £34.95, \$49.95 (pbk)

\section{Avian Ecology and Conservation in an Urbanizing World}

edited by John M. Marzluff, Reed Bowman

\& Roarke Donnelly

Kluwer, £112, \$159.95

\section{Fungal Conservation: Issues and Solutions}

edited by D. Moore, M. M. Nauta, S. E. Evans \& M. Rotheroe

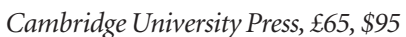

\section{Science in culture}

\section{Scope for sentiment}

Joseph Wolf's illustrations of animals in action. Martin Kemp

There seems to be a sharp contrast between the Victorian fondness for sentimental depictions of anthropomorphized animals and the hard objectivity of professional natural history in the mid-nineteenth century. Little apparently links the tough impersonality of darwinian 'natural selection' and the personalized beasts of Sir Edwin Landseer, famed for such paintings as The Monarch of the Glen. When we find these two poles represented in the work of one artist-illustrator, Joseph Wolf, we may wonder how he was able to accommodate such visual schizophrenia. I believe his work actually points us towards a reassessment of both the sentiment and the science.

Born and educated in Germany, Wolf enjoyed an immensely successful career in London from 1848 to 1899 . He collaborated with some of the great naturalists of his day, including John Gould, Philip Gosse, Herman Schlegel and Daniel Elliot, providing them with great coloured lithographs of striking precision, and he long served as the chief illustrator for the Proceedings of the Royal Zoological Society. Yet his paintings, exhibited at the Royal Academy in London, tell affectingly emotional stories of the struggles between predator and prey in oftenhostile environments, and his popular-book illustrations verge on animal capers.

The peak of Wolf's popularity came with The Life and Habits of Wild Animals, published in 1873 as a grand picture book with 20 woodcuts. Inquisitive Neighbours is typical of both the narrative quality of the illustrations and their humanizing titles. When we realize that the text - no less evocative and vivid in bringing the characters of the animals to life - was by the eminent American naturalist Daniel Elliot, for whom Wolf had previously undertaken five suites of illustrations, the schism between popular art and observational science is less clear cut.

Wolf himself claimed that, to depict creatures in lifelike action and interaction, the artist needed an accurate knowledge of the structures that give rise to their motion. He was scathing of those who know only "the map of an animal", such as those "ornithologists who don't recognize nature - don't know a bird when flying. A specimen must be well dried before they recognise it."

Even the apparently 'arty' expressions join seamlessly with scientific concerns, in particular with Wolf's engagement as one of the illustrators for Darwin's The Expression of the Emotions in Man and Animals, published just a year before his own Wild Animals. Darwin provides unexpected succour for those who sensed a similarity between the way human and animal emotions are manifested:

"No doubt as long as man and all other animals are viewed as independent creations, an effective stop is put to our natural desire to investigate as far as possible the causes of expressions. With mankind some expressions, such as the bristling of the hair under the influence of extreme terror, or the uncovering of the teeth under that of furious rage, can hardly be understood except on the belief that man once existed in a much lower animal-like condition."

When we react with empathy to the threatened dove's puffed out chest and the alertly raised 'eyebrows' of the intruding squirrels, we are playing precisely to the kind of basic expressions for which Darwin was defining the mechanisms.

If the more sentimentalizing aspects of Wolf's art can be shown to adhere to scientific research, so we might surmise that Darwin's own picture of a nature in full-blooded interaction is unthinkable without the Romantic vision of those earlier artists, such as George Stubbs and Eugène Delacroix, who precociously delighted in vicious competition between the powerful and the weak, and the armed and the defenceless. Martin Kemp is in the Department of the History of Art, University of Oxford, Oxford OX1 2BE, UK.

Visualizations: The Nature Book of Art and Science is a collection of essays edited by Martin Kemp (published by Oxford University Press and the University of California Press; $£ 20, \$ 35$ ).

Wolf's Inquisitive Neighbours, typical of his evocative depiction of animals.

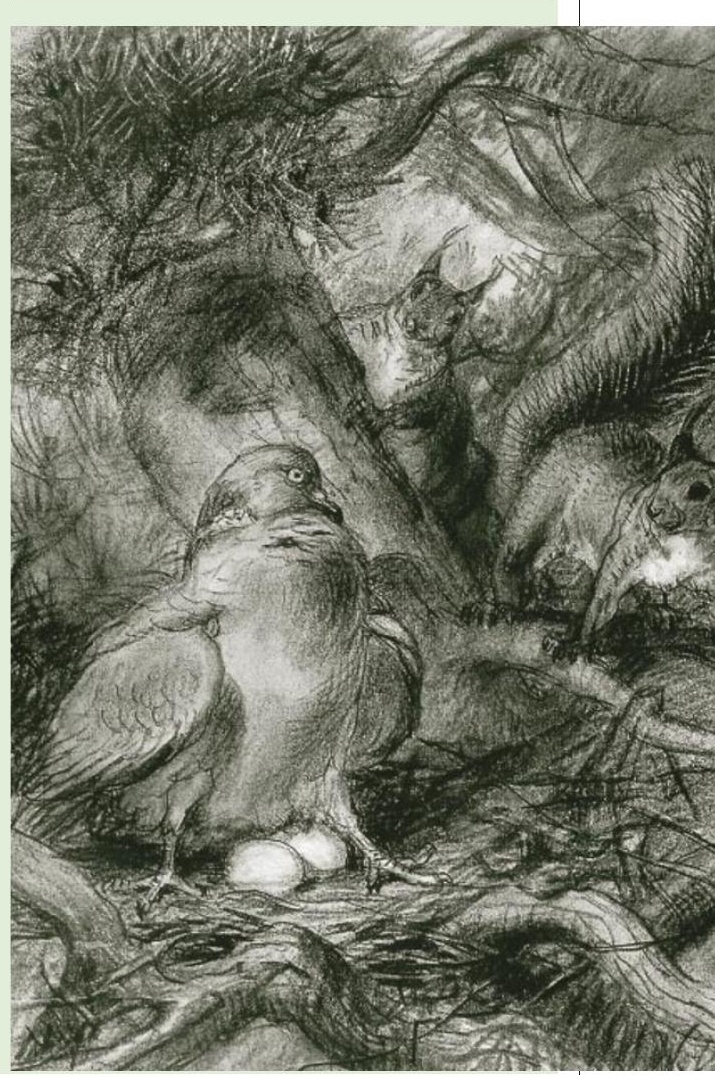

